\title{
Analisis Rasio Solvabilitas Untuk Menilai Kinerja Perusahaan (Studi Kasus Pada PT.Wahana Sentana Baja)
}

\author{
Dina Satriani $^{1}$, Vina Vijaya Kusuma ${ }^{2}$ \\ ${ }^{1}$ Program Studi Komputerisasi Akuntansi STTIKOM Insan Unggul Cilegon, ${ }^{2}$ Program Studi \\ Sistem Informasi STTIKOM Insan Unggul Cilegon

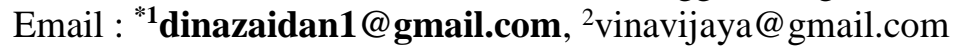

\begin{abstract}
Abstrak
PT. Wahana Sentana Baja adalah perusahaan transportasi peyedia jasa pengangkutan barang produksi sampai ke luar pulau, angkutan bisa melalui darat, laut, maupun udara. Tujuan dalam penelitian ini untuk proses perhitungan dalam menganalisis akuntansi hutang jangka panjang dan sebagai salah satu faktor pengambilan keputusan untuk meminjam dana yang jatuh tempo lebih dari satu tahun pada PT. Wahana Sentana Baja. Pengumpulan data memakai metode deskriptif dan teknik pengumpulan data, dari wawancara, pengamatan langsung, dan buku referensi. Dalam proses perhitungan dan pengambilan keputusan dilihat dari laporan keuangan, yaitu laporan laba rugi dan laporan neraca pada tahun 2016, 2017, 2018. Kemudian dianalisis memakai rasio solvabilitas yang dibagi menjadi tiga bagian rasio total hutang atas modal sendiri, rasio total hutang atas total aktiva, dan rasio hutang jangka panjang atau modal sendiri.
\end{abstract}

Kata Kunci : Laba Rugi, Neraca, Rasio Solvabilitas, Rasio Total Hutang

\begin{abstract}
PT. Wahana Sentana Baja is a transportation company that provides transportation services for production of goods to the outside, transportation can be by land, sea, or air. The purpose of this study is for the calculation process in analyzing long-term debt accounting and as a decision-making factor to borrow maturing funds. more than one year at PT. Wahana Sentana Baja. Data collection using descriptive methods and data techniques, interviews, direct interviews, and reference books. The process of decision making and decision making is seen from the financial statements, namely the profit and loss report and the balance sheet in 2016, 2017, 2018. Then it is analyzed using the solvency ratio which is divided into three parts, the ratio of debt to equity, ratio of total debt to total assets, and ratio long-term debt or equity.
\end{abstract}

Keywords : Profit and Loss, Balance Sheet, Solvency Ratio, Total Debt Ratio.

\section{PENDAHULUAN}

Dalam menganalisis laporan keuangan terdapat akuntansi hutang yang didalamnya memuat hutang-hutang perusahaan, dimana hutang tersebut dibutuhkan untuk memenuhi operasional perusahaan dalam kurun periode tertentu. Perbedaan hutang jangka pendek dan hutang jangka panjang, yaitu hutang jangka pendek adalah kewajiban yang diharapkan dibayar menggunakan sumber dana berasal dari aset lancar atau kurang dari satu periode buku akuntansi, sebaliknya hutang jangka panjang merupakan suatu kewajiban yang dibayarkan jangka waktu yang cukup lama. suatu siklus normal dapat menimbulkan aktiva tidak lancar dengan jangka waktu lebih dari setahun. 
Perusahaan membutuhkan rangkaian periode tertentu dalam hutang jangka panjang untuk proses analisis. Menganalisis hutang jangka panjang dibutuhkan metode-metode untuk mendapatkan hasil yang semaksimal mungkin dengan teliti, akurat, dan memuaskan. PT. Wahana Sentana Baja adalah perusahaan jasa yang bergerak dibidang jasa transportasi untuk impor dan ekspor ke suatu wilayah. Perusahaan tersebut pasti membeli alat bantu operasional jasa, seperti pembelian transportasi beberapa truk untuk mengangkut bahan baku dengan jangka waktu pembayarannya lama lebih dari satu tahun buku akuntansi. Perbandingan neraca akuntansi hutang jangka panjang bisa dilihat dari laporan keuangan PT. Wahana Sentana Baja yang jangka waktunya lebih dari tiga periode atau tiga tahun untuk mengetahui hasil perbandingan tahun ke tahun. Dalam tiga periode tersebut bias dilihat perbandingan dengan metode yang ada pada PT. Wahana Sentana Baja. Metode yang dipakai untuk melihat perbandingan adalah Microsoft excel yang sudah diubah otomatis menjadi Microsoft excel formulas and functions.

\subsection{Rumusan Masalah}

Rumusan masalah didapat dari permasalahan dari kasus yang diteliti meliputi :

1. Bagaimana proses penghitungan analisis akuntansi hutang jangka panjang pada PT. Wahana Sentana Baja?

2. Bagaimana analisis akuntansi hutang jangka panjang dapat digunakan sebagai salah satu proses pengambilan keputusan perusahaan?

\subsection{Landasan Teori Dan Literature Review Yang Terkait Dengan Penelitian Yang Diteliti Landasan Teori \\ 1. Jenis-Jenis Rasio Keuangan}

Dari Buku Pengantar Manajemen Keuangan: Edisi Kedua, Pencipta Kasmir (2016) halaman 112. Jenis rasio keuangan dapat digunakan untuk menilai kinerja perusahaan berbeda-beda. rasio keuangan ini digunakan sesuai dengan kebutuhan perusahaan.

Dalam mengukur kinerja suatu perusahaan dapat menggunakan berbagai rasio keuangan, yang akan memberikan arti tertentu tentang posisi yang diinginkan. Berikut adalah jenis-jenis rasio keuangan, yaitu:
a) Rasio Likuiditas;
c) Rasio Solvabilitas (Leverage);
e) Rasio Aktivitas;
b) Rasio Profitabilitas;
d) Rasio Pertumbuhan;
f) Rasio penilaian

Penelitian ini, memakasi rasio solvabilitas atau leverage ratio untuk mengambil salah satu keputusan dalam analisis hutang jangka panjang.

\section{Rasio Solvabilitas}

Dari buku Analisis Laporan Keuangan (2016) yang diciptakan oleh Hary, SE, halaman 163. Perusahaan dengan rasio solvalitas yang tinggi dapat terdampak pada timbulnya resiko keuangan yang besar, tetapi mempunyai peluang besar juga menghasilkan laba yang tinggi.

Rasio Solvabilitas dipergunakan untuk mengukur berapa besarnya beban utang yang harus dittanggung perusahaan untuk memenuhi aset.

Berikut beberapa implikasi dari rasio ini :

a) Kreditor melihat dari jumlah ekuitas debitor sebagai margin keamanan,

b) Kontrol atas perusahaan akan tetap berada di tangan debitur jika sumber dananya berasal dari pinjaman atau hutang,

c) Sumber pedanaan yang berasal dari penerbitan dan penjualan saham akan mempengaruhi atau bahkan mengendalikan pemegang saham atas perusahaan.

Jenis-jenis rasio solvabilitas, diantara lain:

a) Total hutang atas total aktiva atau rasio hutang terhadap asset (debt to asset ratio),

b) Total hutang atas modal sendiri atau rasio hutang terhadap ekuitas (debt to equity ratio),

c) Rasio hutang terhadap ekuitas jangka panjang (long term debt to equity ratio), 
d) Rasio Kelipatan atau times interest earned,

e) Lingkup biaya tetap atau Fixed charge coverage.

\section{LITERATURE REVIEW}

1. Hammad, Ani Nuraini (2018) berjudul Analisis Pengaruh Kebijakan Hutang terhadap Kinerja Keuangan Perusahaan. Penelitian ini mempunyai tujuan untuk mengetahui bagaimana pengaruh kebijakan hutang terhadap kinerja keuangan dengan menggunakan 8 sampel perusahaan manufaktur yang terdaftar pada Bursa Efek Indonesia (BEI) dan termasuk dalam indeks LQ45 tahun 2015-2017.

2. Ari Triadi Wijaya dan Muhammad Ali Fikri (2019) berjudul Analisis Pengaruh Kebijakan Hutang Terhadap Kinerja Keuangan. Penelitian ini mempunyai tujuan untuk mengetahui bagaimana pengaruh kebijakan hutang terhadap kinerja keuangan pada perusahaan batu bara yang terdaftar pada Bursa Efek Indonesia (BEI) tahun 2019.

3. Jemmy Poandy, S.E (2019) dengan judul Analisis Hutang Terhadap Kinerja PT. Multi Sukses Makmur Perkasa. Penelitian ini mempunyai tujuan untuk mengetahui kinerja perusahaan dalam menutupi hutang perusahaan.

4. Albahi, SE, M.Si (2015) Analisis Rasio Likudasi, Rasio Rentabilitas, Rasio Solvabilitas pada kinerja keuangan PT. Bank Sumut Cabang Pirngadi Medan. Bertujuan untuk mengetahui kinerja keuangan dihasilkan menggunakan metode rasio.

\subsection{Pemecahan Masalah \\ Objek Penelitian}

Penelitian inilah yang akan diteliti selama kegiatan penelitian. Beberapa masalah perlu dipahami agar dapat menentukan dan menyusun objek penelitian dalam metode penelitian ini dengan baik.

Dalam penelitian ini dilakukan riset pada perusahaan jasa bernama PT. Wahana Sentana Baja dengan beralamat, jalan SA. Tirtayasa, No 146, Istana Cilegon Kav.36, Masigit, Kecamatan Cilegon, Kota Cilegon, Banten 42411, Indonesia.

\section{Penelitian}

Penelitian ini bersifat penelitian deskriptif, penelitian untuk salah satu proses mencatat dan menghitungkan analisis akuntansi hutang jangka panjang pada PT. Wahana Sentana Baja.

Penelitian deskriptif kajian yang bertujuan untuk mendeskripsikan fenomena yang ada, yang terjadi saat ini atau di masa lampau. Kajian ini tidak memanipulasi atau mengubah variabel independen, tetapi mendeskripsikan suatu kondisi sebagaimana adanya yang dapat menggambarkan kondisi individu atau menggunakan angka.

\section{METODE PENELITIAN}

\subsection{Metode Pengumpulan Data}

Agar bisa menghasilkan penelitian yang teliti dan hasil memuaskan, beberapa metode pengumpulan data pada penelitian ini, diantara lain:

1) Metode Obsevarsi (Pengamatan langsung)

Melakukan pengamatan langsung ke lokasi untuk mendapatkan data yang dibutuhkan agar memperoleh informasi yang akurat untuk menjawab permasalahan pada penelitian ini

2) Metode Wawancara

Dengan wawancara, informasi yang bisa didapatkan dengan cara bertanya secara langsung kepada sumber wawancara. 
3) Metode Buku Referensi

Buku referensi adalah buku yang berisi informasi yang ringkas dan padat seperti ensiklopedia, kamus, atlas, dan jenis manual lainnya. Buku yang berisi informasi yang mudah ditemukan agar pencarian data lebih efisien. Kualitas buku referensi tidak ditentukan oleh bagaimana buku itu ditulis. dilakukan, tetapi lebih dari jumlah data dan data referensi secara komparatif

\section{HASIL DAN PEMBAHASAN}

\subsection{Pelaksanaan Analisis Akuntansi Hutang Jangka Panjang Pada PT. Wahana Sentana Baja}

Menganalisis akuntansi hutang jangka panjang pada PT. Wahana Sentana Baja bertujuan untuk mengambil salah satu keputusan baik atau buruk keuangan perusahaan tersebut.Pengambilan keputusan dilihat dari laporan keuangan, yaitu laporan labarugi dan laporan neraca pada tahun 2016, 2017, 2018, kemudian menggunakan rasio solvabilitas.

Rasio solvabilitas terdiri dari :

a) Debt to Equity Ratio atau Rasio Total Hutang Atas Modal Sendiri.

Ratio yang mengukur dalam menganalisis laporan keuangan untuk memperlihatkan besar jaminan yang tersedia untuk kreditor, yaitu total hutang dibagi dengan modal itu sendiri.

b) Debt To Assets Ratio atau Rasio Total Hutang Atas Total Aktiva

Rasio Debt to Assets Ratio disebut juga sebagai rasio yang melihat perbandingan hutang perusahaan, yaitu diperoleh dari perbandingan total hutang dibagi dengan total aktiva.

c) Long Term to Total Equity Ratio atau Rasio Hutang Jangka Panjang Atas Modal sendiri.

Rasio yang mengukur bagian dari modal sendiri yang menjamin untuk hutang jangka panjang.

Langkah dari pelaksanaan rasio solvabilitas dilihat dari cara melihat laporan labarugi dan laporan neraca. Keduanya dianalisis, sehingga mendapatkan hasil yang bisa digunakan untuk mengambil keputusan.

\section{Laporan Laba Rugi}

PT. Wahana Sentana Baja

Laporan LabaRugi

Periode 31 Desember tahun 2016, 2017 dan 2018

\begin{tabular}{|c|c|c|c|c|}
\hline Nama Akun & Catatan & Tahun 2016 & Tahun 2017 & Tahun 2018 \\
\hline Pendapatan & 19 & Rp 94.428.796.576,00 & Rp 101.703.189.026,00 & Rp 117.875.876.155,00 \\
\hline Beban Pokok Pendapatan & 20 & Rp 77.817.881.641,00 & Rp $84.726 .998 .609,00$ & Rp $98.587 .852 .738,00$ \\
\hline Laba Kotor & & Rp 16.610.914.935,00 & $\begin{array}{ll}R p & 16.976 .190 .417,00 \\
\end{array}$ & $\begin{array}{ll}\mathrm{Rp} & 19.288 .023 .417,00 \\
\end{array}$ \\
\hline Beban Usaha & 21 & & & \\
\hline \# Beban Pemasaran & & $409.910 .783,00$ & $551.237 .218,00$ & $459.710 .137,00$ \\
\hline \# Beban Administrasi \& Umum & & $\operatorname{Rp} 6.321 .949 .258,00$ & 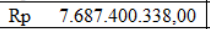 & $\begin{array}{ll}\mathrm{Rp} & 8.463 .208 .696,00 \\
\end{array}$ \\
\hline \# Beban Penyusutan & & Rp $\quad 94.329 .804,00$ & $92.031 .000,00$ & $79.095 .409,00$ \\
\hline Jumlah Beban Usaha & & $\begin{array}{ll}R_{p} & 6.826 .189 .845,00 \\
\end{array}$ & $8.330 .668 .556,00$ & $9.002 .014 .242,00$ \\
\hline Laba Usaha & & Rp $9.784 .725 .090,00$ & $8.645 .521 .861,00$ & $\begin{array}{ll}R p & 10.286 .009 .175,00 \\
\end{array}$ \\
\hline Pendapatan(Beban) Lainnya & 22 & & & \\
\hline \# pendapatan lain lainnya & & $\begin{array}{ll}\text { Rp } & 699.105 .358,00 \\
\end{array}$ & $655.256 .430,00$ & $1.054 .190 .265,00$ \\
\hline \# Beban lain lainnya & & -Rp $2.508 .005 .532,00$ & $2.804 .262 .406,00$ & $1.959 .681 .914,00$ \\
\hline Jumlah Pendapatan(Beban) lainnya & & $\begin{array}{ll}-R p & 1.808 .900 .174,00 \\
\end{array}$ & $2.149 .005 .976,00$ & $905.491 .649,00$ \\
\hline Laba Bersih Sebelum Pajak & & Rp $7.975 .824 .916,00$ & $6.496 .515 .885,00$ & $9.380 .517 .526,00$ \\
\hline Pajak Kini & 13 & Rp $2.141 .321 .286,00$ & $2.306 .119 .490,00$ & $2.564 .875 .094,00$ \\
\hline Pajak Tangguhan & 13 & Rp $\quad 279.831 .904,00$ & $98.267 .986,00$ & $133.211 .414,00$ \\
\hline Laba Bersih setelah Pajak & & Rp 5.554.671.726,00 & 4.092.128.409,00 & $6.948 .853 .846,00$ \\
\hline Keuntungan(kerugian) penilaian kembali aktuarial & & $\begin{array}{ll}-R p & 757.590 .363,00 \\
\end{array}$ & $393.035 .945,00$ & $77.558 .484,00$ \\
\hline Manfaat(beban) Pajak Tangguhan & & Rp $\quad 189.397 .591,00$ & $187.093 .732,00$ & \\
\hline Keuntungan(kerugian) penilaian kembali aktuarial setelah pajak & & -Rp $\quad 568.192 .772,00$ & $580.129 .677,00$ & $77.558 .484,00$ \\
\hline Jumlah Pajak Komprehensif & & Rp 4.986.478.954,00 & $3.511 .998 .732,00$ & 6.871.295.362,00 \\
\hline
\end{tabular}

Gambar 1. Laporan LabaRugi

Sumber : PT. Wahana Sentana Baja 


\section{Laporan Neraca}

PT. Wahana Sentana Baja

Neraca

Periode 31 Desember 2016, 2017, dan 2018

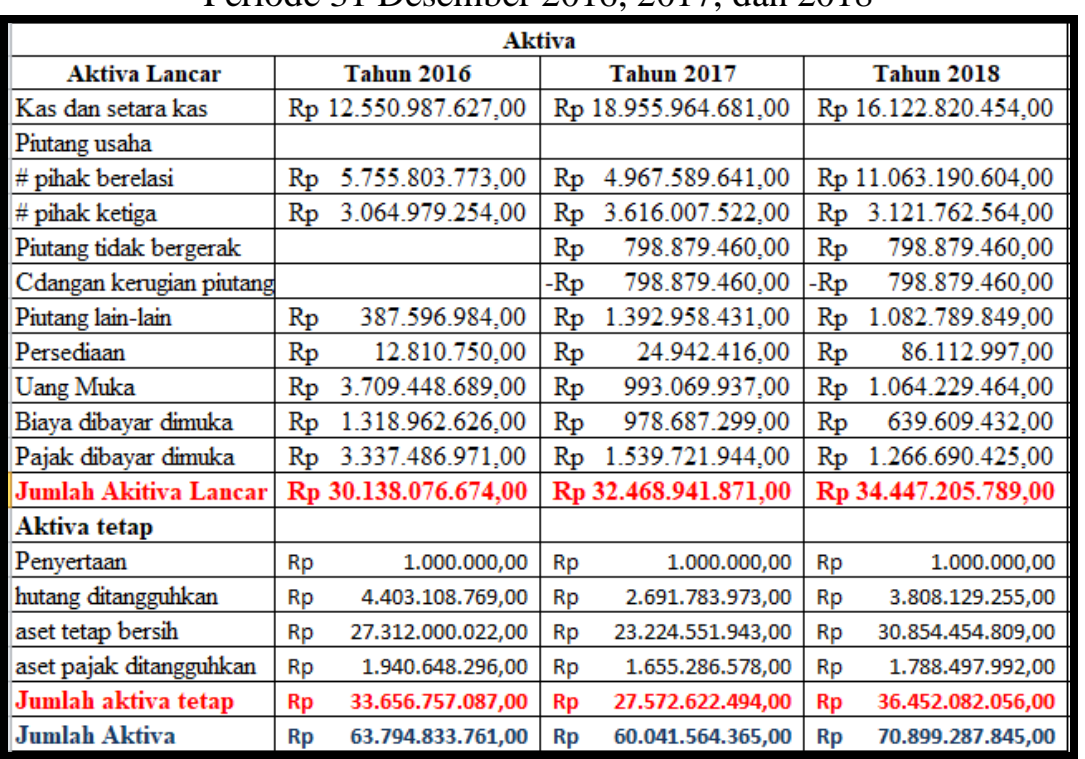

Gambar 2. Aktiva PT. Wahana Sentana Baja

Sumber : PT. Wahana Sentana Baja

\begin{tabular}{|c|c|c|c|}
\hline \multicolumn{4}{|c|}{$\begin{array}{r}\text { Passiva } \\
\end{array}$} \\
\hline Hutang Lancar & Tahun 2016 & Tahun 2017 & Tahun 2018 \\
\hline \multicolumn{4}{|l|}{ Hutang Usaha } \\
\hline \# pihak berelasi & $\mathrm{Rp} \quad 1.542 .921 .594,00$ & $1.308 .737 .229,00$ & Rp $1.297 .840 .746,00$ \\
\hline \# pihak ketiga & Rp $3.273 .670 .955,00$ & $2.950 .012 .480,00$ & $\begin{array}{ll}\mathrm{Rp} & 2.117 .148 .514,00 \\
\end{array}$ \\
\hline Hutang jatuh tempo 1 tahun & Rp $\quad 4.894 .111 .500,00$ & $4.894 .781 .827,00$ & Rp $7.285 .662 .480,00$ \\
\hline Hutang Pajak & Rp $\quad 570.833 .936,00$ & $486.264 .539,00$ & Rp $\quad 816.849 .018,00$ \\
\hline Beban yang harus dibayar & $\begin{array}{ll}\text { Rp } & 5.873 .436 .431,00 \\
\end{array}$ & $6.485 .000 .118,00$ & Rp $7.762 .444 .215,00$ \\
\hline Hutang Lancar Lainnya & Rp $\quad 3.360 .355 .399,00$ & $\begin{array}{ll}\mathrm{Rp} & 2.202 .374 .402,00 \\
\end{array}$ & Rp $\quad 2.762 .115 .413,00$ \\
\hline Jumlah Hutang Lancar & Rp 19.515.329.815,00 & Rp $18.327 .170 .595,00$ & Rp 22.042.060.386,00 \\
\hline \multicolumn{4}{|l|}{ Hutang Tidak Lancar } \\
\hline Hutang imbalan pasca kerja & Rp $\quad 6.206 .123 .361,00$ & $\mathrm{Rp} \quad 7.194 .805 .110,00$ & Rp 7.394.257.745,00 \\
\hline Hutang Jangka Panjang & Rp 15.207.501.101,00 & Rp $10.391 .710 .444,00$ & Rp 14.463.796.136,00 \\
\hline Jumlah hutang tidak lancar & Rp 21.413.624.462,00 & Rp $17.586 .515 .554,00$ & Rp 21.858.053.881,00 \\
\hline Modal saham & Rp $7.983 .500 .000,00$ & Rp $\quad 7.983 .500 .000,00$ & Rp $7.983 .500 .000,00$ \\
\hline Saldo laba ditahan & Rp 11.150.298.087,00 & Rp $14.454 .969 .814,00$ & Rp 14.547.098.222,00 \\
\hline Laba tahun berjalan & Rp $\quad 5.554 .671 .726,00$ & Rp $\quad 4.092 .128 .408,00$ & Rp $\quad 6.948 .853 .846,00$ \\
\hline Modal lain-lain & -Rp $\quad 1.822 .590 .329,00$ & -Rp $\quad 2.402 .720 .006,00$ & $\begin{array}{ll}-R p & 2.480 .278 .490,00 \\
\end{array}$ \\
\hline Jumlah Modal & Rp 22.865.879.484,00 & Rp 24.127.878.216,00 & Rp 26.999.173.578,00 \\
\hline Jumlah Passiva & Rp 63.794.833.761,00 & Rp $60.041 .564 .365,00$ & Rp 70.899.287.845,00 \\
\hline
\end{tabular}

Gambar 3. Passiva PT. Wahana Sentana Baja

Sumber : PT. Wahana Sentana Baja

\subsection{Leverage Ratio atau Rasio Solvabilitas}

Rasio solvabilitas terdiri dari rasio total hutang atas modal sendiri atau debt to equity ratio, rasio total hutang atas total aktiva atau debt total assets ratio, dan rasio total hutang jangka panjang long term to total equity ratio.

Laporan Keuangan PT. Wahana Sentana Baja yang digunakan dalam analisis rasio solvabilitas, yaitu laporan neraca periode tahun 2016 sampai 2018 sebanyak tiga tahun.

a) Total Debt to Equity Ratio

Perhitungan dari Total Debt to Equity Ratio, yaitu:

Total Hutang x $100 \%$

Tahun $2016=\underline{\operatorname{Rp} \quad 40.928 .954 .277} \times 100 \%$

Modal sendiri 
Rp. 22.865.879.484

$$
=1,79 \%
$$

Hal ini pada tahun 2016 menunjukan bahwa Rp. 1 modal sendiri mengandung total hutang sebanyak Rp. 0,0179. Secara total debt to equity ratio PT. Wahana Sentana Baja, solvable.

$$
\begin{aligned}
\text { Tahun } 2017 & =\frac{\operatorname{Rp~} 35.913 .686 .149}{\text { Rp. } 24.127 .878 .216} \times 100 \% \\
& =1,49 \%
\end{aligned}
$$

Hal ini pada tahun 2017 menunjukan bahwa Rp. 1 modal sendiri mengandung total hutang sebanyak Rp. 0,0149. Secara total debt to equity ratio PT. Wahana Sentana Baja, solvable.

$$
\begin{aligned}
\text { Tahun } 2018= & =\frac{\operatorname{Rp} 43.900 .114 .267}{\operatorname{Rp} .26 .999 .173 .578} \times 100 \% \\
& =1,63 \%
\end{aligned}
$$

Hal ini pada tahun 2018 menunjukan bahwa Rp. 1 modal sendiri mengandung total hutang sebanyak Rp. 0,0163. Secara total debt to equity ratio PT. Wahana Sentana Baja, solvable.

b) Total Debt to Asset Ratio

Perhitungan dari Total Debt toAsset Ratio, yaitu: Total Hutang x 100\%

$$
\begin{aligned}
\text { Tahun } 2016= & \frac{\operatorname{Rp} \quad 40.928 .954 .277}{\text { Rp. } 63.794 .833 .761} \times 100 \% \\
& =0,64 \%
\end{aligned}
$$

\section{Total Aktiva}

Hal ini pada tahun 2016 menunjukan bahwa Rp. 1 total aktiva mengandung total hutang sebanyak Rp. 0,0064. Secara total debt to asset ratio PT. Wahana Sentana Baja, solvable.

$$
\begin{aligned}
\text { Tahun } 2017= & \frac{\text { Rp } 35.913 .686 .149}{\text { Rp. } 60.041 .564 .365} \times 100 \% \\
& =0,60 \%
\end{aligned}
$$

Hal ini pada tahun 2017 menunjukan bahwa Rp. 1 total aktiva mengandung total hutang sebanyak Rp. 0,006. Secara total debt to asset ratio PT. Wahana Sentana Baja, solvable.

$$
\begin{aligned}
\text { Tahun } 2018 & =\frac{\operatorname{Rp} 43.900 .114 .267}{\operatorname{Rp} .70 .899 .287 .845} \times 100 \% \\
& =0,62 \%
\end{aligned}
$$

Hal ini pada tahun 2018 menunjukan bahwa Rp. 1 total aktiva mengandung total hutang sebanyak Rp. 0,0062. Secara total debt to asset ratio PT. Wahana Sentana Baja, solvable.

c) Long Term Debt to Total Equity Ratio

Perhitungan dari Long Term Debt to Equity Ratio, yaitu:

$=\underline{\text { Hutang Jangka Panjang } \times 100 \%}$

$$
\text { Modal sendiri }
$$

Tahun $2016=\underline{\text { Rp. } 21.413 .624 .462} \times 100 \%$

$$
\text { Rp. 22.865.879.484 }
$$

$$
=0,94 \%
$$


Hal ini pada tahun 2016 menunjukan bahwa Rp. 1 modal sendiri mengandung hutang jangka panjang sebanyak Rp. 0,0094. Secara long term to total equity ratio PT. Wahana Sentana Baja, solvable.

$$
\begin{aligned}
\text { Tahun } 2017= & \frac{\text { Rp. } 17.586 .515 .554}{\text { Rp. } 24.127 .878 .216} \times 100 \% \\
& =0,73 \%
\end{aligned}
$$

Hal ini pada tahun 2017 menunjukan bahwa Rp. 1 modal sendiri mengandung hutang jangka panjang sebanyak Rp. 0,0073. Secara long term to total equity ratio PT. Wahana Sentana Baja, solvable.

$$
\begin{aligned}
\text { Tahun } 2018= & \frac{\text { Rp. } 21.858 .053 .881}{\text { Rp. } 26.999 .173 .578} \times 100 \% \\
& =0,81 \%
\end{aligned}
$$

Hal ini pada tahun 2018 menunjukan bahwa Rp. 1 modal sendiri mengandung hutang jangka panjang sebanyak Rp. 0,0081. Secara long term to total equity ratio PT. Wahana Sentana Baja, solvable.

\section{Analisis Hutang Jangka Panjang}

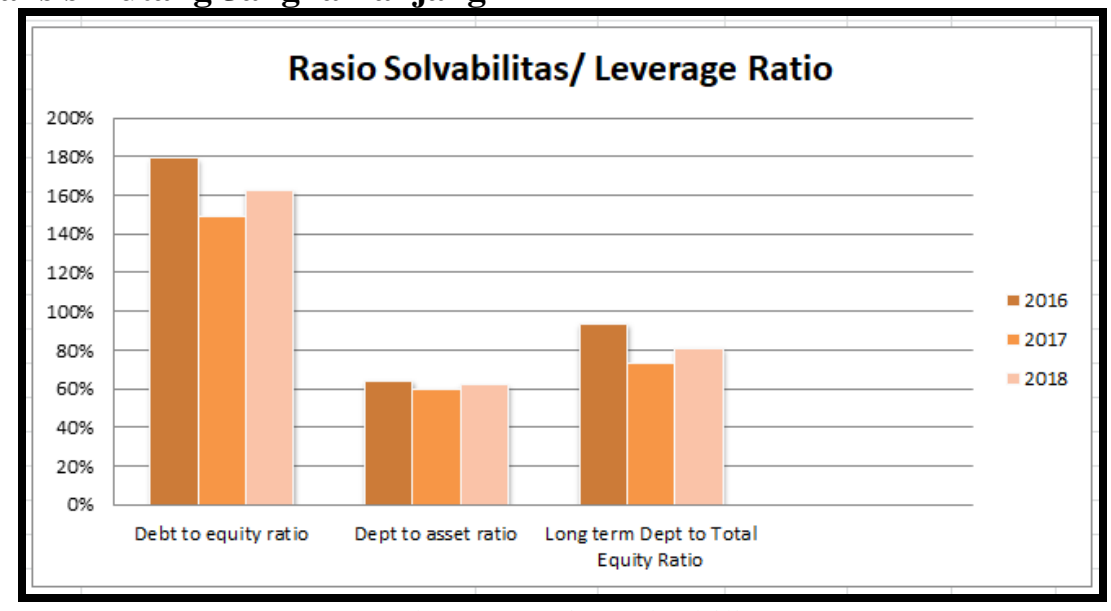

Gambar 4. Rasio Solvabilitas

Sumber: Perhitungan perbandingan rasio solvabilitas

Dari Diagram batang di atas, bisa melihat kesimpulan dalam menganalisis hutang jangka panjang. Diantara lain;

a) Total Debt to Equity Ratio (Rasio Total Hutang atas Modal Sendiri)

Tabel 1. Total Debt to Equity Ratio

\begin{tabular}{|c|c|}
\hline Tahun & \multicolumn{1}{|c|}{ Rasio } \\
\hline 2016 & $179 \%$ \\
\hline 2017 & $149 \%$ \\
\hline 2018 & $163 \%$ \\
\hline
\end{tabular}

Berdasarkan dari total debt to equity ratio pada tahun 2016, 2017, dan 2018, solvable.Karena pada 3 tahun tersebut perusahaan PT. Wahana Sentana Baja dapat membayar seluruh kewajiban baik jangka pendek maupun jangka panjang.

b) Total Debt to Asset Ratio (Rasio Total Hutang atas Total Aktiva)

Tabel 2. Total Debt to Asset Ratio 


\begin{tabular}{|c|c|}
\hline Tahun & Rasio \\
\hline 2016 & $64 \%$ \\
\hline 2017 & $60 \%$ \\
\hline 2018 & $62 \%$ \\
\hline
\end{tabular}

Berdasarkan total debt to asset ratio pada tahun 2016, 2017, dan 2018. Dalam analisis 3 tahun tersebut, perusahaan PT. Wahana Sentana Baja mampu menutupi seluruh hutang atas total aktiva yang dimiliki.

c) Long Term Debt to Total Equity (Rasio Total Hutang Jangka Panjang atas Modal Tabel 3. Long Term Dept to Total Equity Ratio

\begin{tabular}{|c|c|}
\hline Tahun & Rasio \\
\hline 2016 & $94 \%$ \\
\hline 2017 & $73 \%$ \\
\hline 2018 & $81 \%$ \\
\hline
\end{tabular}

Berdasarkan long term debt to asset ratio pada tahun 2016, 2017, dan 2018.Dalam analisis 3 tahun tersebut, perusahaan PT. Wahana Sentana Baja solvable untuk membayar hutang jangka panjang mereka.

\section{KESIMPULAN}

Penelitian analisis akuntansi hutang jangka panjang pada PT. Wahana Sentana Baja bisa disimpulkan sebagai berikut:

1. Proses penghitungan dari analisis akuntansi hutang jangka panjang pada PT. Wahana Sentana Baja, yaitu dilihat dari analisis rasio solvabilitas atau leverage ratio pada data tiga tahun sebelumnya, 2016, 2017, dan 2018. Rasio solvabilitas atau leverage ratio dibagi menjadi tiga bagian, yaitu debt to equty ratio atau rasio total hutang atas modal sendiri, debt to total assets ratio atau rasio total hutang pada total aktiva, dan long term to equity ratio atau rasio hutang jangka panjang atas modal.

2. Analisis hutang jangka panajang salah satu dalam pengambilan keputusan PT. Wahana Sentana Baja dengan berdasarkan dari total debt to equity ratio tahun 2016, 2017, dan 2018, solvable. Karena pada 3 tahun tersebut perusahaan PT. Wahana Sentana Baja dapat membayar seluruh kewajiban dalam jangka panjang maupun jangka pendek. Kemudian berdasarkan total debt to asset ratio pada tahun 2016, 2017, dan 2018. Dalam analisis 3 tahun tersebut, perusahaan PT. Wahana Sentana Baja mampu menutupi seluruh hutang atas total aktiva yang dimiliki dan terakhir, berdasarkan long term debt to asset ratio pada tahun 2016, 2017 dan 2018. Dalam analisis 3 tahun tersebut, perusahaan PT. Wahana Sentana Baja solvable untuk membayar hutang jangka panjang mereka.

\section{SARAN}

Penelitian analisis akuntansi hutang jangka panjang pada PT. Wahana Sentana Baja dapat melihat beberapa saran, diantara lain:

1. Lakukan analisis laporan keuangan secara berkala baik rasio likuiditas, rasio solvabilitas, rasio aktivitas, dan rasio profitabilitas dengan tujuan perumusan, agar bisa melihat kondisi keuangan perusahaan sehat atau tidak.

2. Adanya audit internal maupun ektrenal terikat dalam membuat perhitunagn laporan keuangan, sehingga bisa meminimalisir keuangan perusahaan. 


\section{DAFTAR PUSTAKA}

[1] Aditya, A. 2020. Rekayasa Perangkat Lunak. Jakarta: Andri Aditya

[2] Fitrah, M. 2017. Metodologi Penelitian. Sukabumi: Jejak Publisher.

[3] Hartono. 2018. Pengantar Akuntansi. Yogyakarta: Deepublish.

[4] Ikasari, N. 2016. Pengantar Akuntansi 2. Jakarta: Prenadamedia Group.

[5] Kasmir. 2016. Pengantar manajemen keuanganan: edisi kedua. Jakarta: Prenadamedia Group.

[6] Hary. 2016. Analisis Laporan Keuangan. jakarta : PT Grasindo

[7] Shatu, Y. P. 2016. Kuasai Detail Akuntansi Laba dan Rugi. Jakarta: Pustaka Ilmu Semesta.

[8] Sumiati. 2019. Manajemen Keuangan Perusahaan. Malang: UB Press.

[9] Suratno. 2019. Bahan Praktikum Akuntansi Perusahaan Jasa. Malang: CV. IRDH.

[10] Untari, D. T. 2018. Metodologi Penelitian. Banyumas: Pena Persada Redaksi 